\title{
An Assessment of the Impact of an Animation on Biology Students' Visualization Skills Related to Basic Concepts of Mitosis
}

\author{
Lindelani Mnguni ${ }^{1 *}$, Dudrah Moyo ${ }^{2}$ \\ ${ }^{1}$ Centre for Health Sciences Education, Faculty of Health Sciences, University of the Witwatersrand, SOUTH AFRICA \\ 2 Department of Science \& Technology Education, College of Education, University of South Africa, SOUTH AFRICA
}

Received 27 January $2021 \cdot$ Accepted 23 April 2021

\begin{abstract}
Using external representations (ERs) to foster content understanding in biology education has increased as they allow for the visualization of abstract biological phenomena. However, the extent to which students have visualization skills required to learn from ERs effectively remains an open question. The current quantitative quasi-experimental research sought to determine the extent to which an animation could be used to enhance students' visualization skills and reduce learning difficulties related to basic concepts of mitosis. Participants were 67 Grade 10 purposively selected learners from a South African school. An assessment test was used for data collection. Results showed that exposure to an animation, as an additional learning tool, improved students' visualization skills while reducing visualization difficulties related to basic concepts of mitosis. We conclude that ERs may enhance students' visualization skills, reduce learning difficulties and improve content understanding. ERs may also be used in broader student development which includes visual literacy.
\end{abstract}

Keywords: biology education, external representations, learning difficulties, visual literacy, visualization

\section{INTRODUCTION}

In his cognitive theory of multimedia learning, Mayer (2014, p. 1) states that "people learn more deeply from words and pictures than from words alone." Consequently, the use of external representations (ERs) in biology education has increased significantly over the last fifty years (Anderson et al., 2013; Mnguni, 2019a). ERs refer to discipline-specific semiotics (Mnguni, 2019a), which are processed through predominantly nonverbal, visual cognitive processes described in the dual coding theory (Mayer, 2014; Paivio, 2007). ERs include learning aids such as written text, diagrams, pictures, symbols, and animations, which are used to represent scientific phenomena for communicating, teaching, learning, and research. In biology education, ERs are used to depict abstract biological phenomena that exist at microscopic and molecular levels, which would otherwise not be visualized without an aided naked eye (Anderson et al., 2013; Tsui \& Treagust, 2003). As such, researchers, instructional and curriculum designers rely on "a complex system of semiotics, which includes written language, images, and symbols to represent discipline-specific knowledge" (Mnguni, 2019a, p. 122) for the construction of meaningful and scientifically sound mental models (Anderson et al., 2013). The current manuscript explores the use of an animation as an additional teaching tool to develop skills required for effective learning through ERs. This study is particularly necessitated by the increasing use of online learning, which utilizes ERs such as animations.

\section{Learning through External Representations}

The extent to which ERs are useful research, teaching and learning aids depend on several factors, including the efficiency of the nonverbal visual cognitive processes described in the dual coding theory, limited capacity theory, and the cognitive theory of multimedia learning (Mayer, 2014). Additionally, visual literacy, which includes visualization skills, plays a significant role in ensuring that students can learn effectively through ERs. Researchers (e.g., Arneson \& Offerdahl, 2018; Avgerinou \& Ericson, 1997) define visual literacy as cognitive

(c) 2021 by the authors; licensee Modestum. This article is an open access article distributed under the terms and conditions of the Creative Commons Attribution License (http://creativecommons.org/licenses/by/4.0/).

\lindelani.mnguni@wits.ac.za (*Correspondence) $\square$ dudrahsimanga@gmail.com 


\section{Contribution to the literature}

- Exposure to an animation as an additional learning tool could improve students' visualization skills in addition to content knowledge.

- Exposure to an animation, as an additional learning tool, could reduce visualization difficulties.

- Animations should be considered for use for the development of visual literacy.

- The findings are particularly important for teachers and instructional designers who have adopted animations as part of their online teaching tools.

abilities that involve decoding and encoding ERs, interpreting ERs as well as creating visual representations of phenomena using pictures, diagrams, and other ERs. However, Mnguni (2019a) argues that because ERs are discipline-specific, visual literacy should also be discipline and context-specific. For example, one's ability to process ER used in mathematics does not necessarily translate to the ability to process ER used in biology.

Consequently, "visual literacy can be defined in terms of discursive fluency, that is when a student understands the various ways in which the discipline generally uses that mode to represent a particular way of knowing" (Airey \& Linder, 2009, p. 33). Arneson and Offerdahl (2018, p. 1) concur with this view by arguing that visual literacy refers to "fluency in the disciplinary discourse," which may be demonstrated through "decoding and interpreting" ERs, "encoding and creating" ERs and generating mental models through visual thinking. It follows, therefore, that a student's visualization skills are dependent on the availability of conceptual knowledge related to the phenomena depicted in the ER (Schönborn \& Anderson, 2009). Such conceptual knowledge would provide a zone of proximal development (Vygotsky, 1978) on which new knowledge could be constructed using an ER as a vehicle for delivering new knowledge. Visualization skills, therefore, refer to the cognitive abilities for a) "inputting of visual information from the external world into the cognitive structures (Internalization of ERs)," b) "processing visual information (Conceptualization of ERs)" cognitively to construct pictorial mental models, and, c) "externalization of information" stored as pictorial mental models (Externalization of ERs) (Mnguni, 2014, p. 3). These cognitive abilities rely on existing prior knowledge, which is used to internalize, conceptualize and externalize new information. Therefore, the effectiveness of ERs as learning tools would depend on prior knowledge and availability of visualization skills.

\section{Assessment and Development of Visualization Skills}

Previous research has shown that visualization skills can be developed and assessed (e.g., Mnguni, 2019a; Mnguni et al., 2016). For example, using the theoretical cognitive process of visualization (Mnguni, 2014) and Bloom's taxonomy (Krathwohl \& Anderson, 2001), Mnguni et al. (2016) were able to identify cognitive skills which are utilized when students learn from ERs in biochemistry. These skills, also known as visualization skills, are associated with visualization stages, namely, internalization, conceptualization, and externalization (Mnguni, 2014). Mnguni (2019a), however, argued that these skills could not be utilized, developed, or assessed independently of discipline-specific content knowledge and semiotics. Mnguni (2019a), therefore, argued that these skills are, in essence, discipline-specific visualization skills as they are utilized when students reason with ER. Subsequently, an instrument to assess these skills was developed (Mnguni, 2019a) and used to determine pre-service teachers' visualization skills in biology (Mnguni, 2019b). Other researchers have also shown that visualization skills can be assessed. For example, Arneson and Offerdahl (2018) developed a Visualization Blooming Tool, which can be used to design teaching and learning activities and assess scientific visual literacy among students. Palmer and Matthews (2015) also developed instructional activities through which students' visual literacy could be developed and evaluated.

While research has shown that visualization skills can be developed and assessed, there remains a dearth of knowledge regarding the extent to which this could be achieved in selected contexts, such as in biology. For example, Milner-Bolotin and Nashon (2012) argue that a significant number of graduate biology students do not develop visualization skills, such as visual-spatial thinking, to a sufficient degree. Milner-Bolotin and Nashon (2012) also cite the National Research Council as suggesting that mathematics and science education do not adequately help students develop visualization skills even though these skills are critical for effective learning in science.

For example, student performance in science subjects has remained a concern in under-resourced schools, particularly in Africa (Prinsloo et al., 2018). This is because schools do not have the necessary infrastructure required to support learning through computer-based ERs such as animations. Additionally, the language of instruction, which is usually English, has a significant impact on student achievement because, for most students, it is a second and even third language (Prinsloo et al., 2018). Because ERs present content in disciplinespecific semiotics, this becomes an additional 'language' that students need to master to learn scientific content 
effectively. Given this, researchers note that in most cases, there are no formal programs to help students develop this visual language and associated visualization skills required for successful learning using ERs. Instead, students are expected to develop visualization skills through passive fortuitous learning. Perhaps, for this reason, previous research has shown a concerning lack of visualization skills among students (Mnguni et al., 2016; Mnguni, 2019b), which could partially explain the high levels of poor performance in science.

It is noteworthy that extensive research has shown that ERs, including animations, could be used to enhance students' content knowledge of scientific phenomena (e.g., Chang et al., 2010; Kühl et al., 2018; Stebner et al., 2017). However, there is limited research regarding the use of these tools to enhance students' visualization skills. For example, Dries et al. (2016) argue that while several biology researchers use ERs for teaching in biology, "few indicate that they explicitly teach" visualization skills. They further argue that unless visualization "is explicitly assessed, there exists the possibility that exam questions test some unknown combination of students' conceptual biochemical understanding and their visual literacy" (Dries et al., 2016, p. 70). Oliver-Hoyo and Babilonia-Rosa (2017) also note that most studies in biology education focus on conceptual understanding without assessing the role of visualization skills in the development of this knowledge. They also report that minimal attention is paid to the use of ERs for the development of visualization skills (Oliver-Hoyo \& Babilonia-Rosa, 2017).

\section{Aims and Research Questions of the Study}

The lack of studies linking the use of ERs and the development of visualization skills in biology necessitated the current research, which sought to explore how an animation could be used to improve students' visualization skills. This research would directly determine whether ERs could enhance the development of visualization skills rather than knowledge alone. The study attempted to respond to the research questions:

a) to what extent could an animation enhance students' visualization skills related to basic concepts of mitosis?

b) to what extent could an animation reduce learning difficulties related to basic concepts of mitosis?

\section{METHODOLOGY}

According to Cresswell (2014), research methodology refers to the broad philosophical perspectives that underpin chosen research methods, including the research paradigm, research approaches, design, and methods used by the researcher. Similarly, Somekh and Lewin (2005, p. 346) suggest that research methodology refers to "the collection of methods or rules by which a particular piece of research is undertaken" as well as the "principles, theories, and values that underpin a particular approach to research." This is supported by Mackenzie and Knipe (2006, p. 5), who argue that "methodology is the overall approach to research linked to the paradigm or theoretical framework while the method refers to systematic modes, procedures or tools used for collection and analysis of data." Consequently, before the research methods are presented, we first reflect on the theoretical framework which guided the current research.

\section{Theoretical Framework}

The current research was guided by Mnguni's (2019a) theoretical framework, which describes learning through ERs (Figure 1). In this framework, learning involves acquiring information from an ER and processing this information in the cognitive structures. Mnguni (2014) suggest that learning through ERs occurs in at least three interrelated cognitive stages, namely, "internalization of visual information from an ER, the conceptualization of this information as well as externalization of information (Mnguni, 2019a, p 124). Internalization of visual information "refers to the process where sense organs, such as the eyes, work with the brain to "absorb" information from" an ER (Mnguni, 2014 , p. 3). Conceptualization of visual information refers to the interpretation and manipulation of the internalized information and its integration with prior knowledge to create new knowledge. Externalization of visual information refers to the process of expressing cognitive information externally through ERs such as drawings (Mnguni, 2014).

Researchers (e.g., Mnguni, 2019; Mnguni et al., 2016) have previously identified and assessed various visualization skills utilized in each of the three stages. These are derived from the taxonomy for teaching, learning, and assessing content knowledge, commonly known as Bloom's taxonomy (Krathwohl \& Anderson, 2001). Schönborn and Anderson (2009) have identified factors that affect students' ability to learn effectively through ERs (Figure 1). These include the availability of content knowledge, students' reasoning skills, and the ER itself. As a result, any successful development and assessment of visualization skills require that students have sufficient content knowledge, the ability to reason effectively with the information presented, and that the ER adheres to basic design principles, such as Moreno and Mayer's (1999) principles of multimedia learning.

Additionally, the ER should be developed in line with Offerdahl et al.'s (2017) taxonomy for characterizing abstraction in instructional representations, suggesting that ERs used in biology can be symbolic, schematic, graphic, cartoon, or realistic. In each category, a specific set of skills is required for students to learn effectively. These skills are similar to 


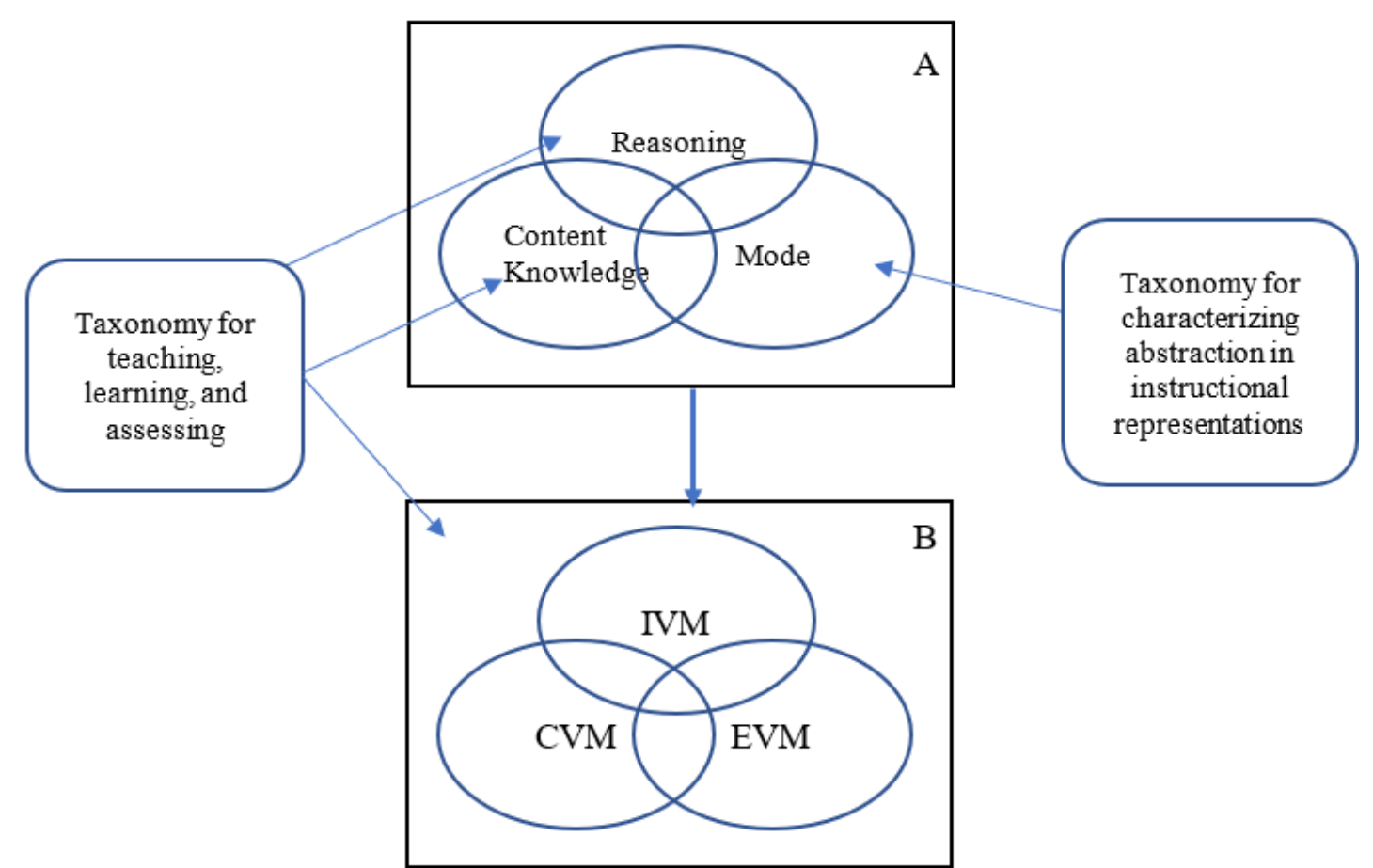

Figure 3. A theoretical framework used in the development of the VSR-b Test. In the framework, 'A' is Schönborn and Anderson's (2009) model of factors determining students' ability to interpret external representations while B is Mnguni's (2014) theoretical cognitive process of visualization (adapted from Mnguni, 2019a)

Table 1. List of visualization skills probed in the current research (adapted from Mnguni, 2018)

\begin{tabular}{|c|c|}
\hline Skill & Definition \\
\hline Analyze & $\begin{array}{l}\text { To systematically break down an ER into essential features by making sense } \\
\text { correct meaning to its components. }\end{array}$ \\
\hline Describe & $\begin{array}{l}\text { To use content knowledge to provide a detailed, comprehensible account of s } \\
\text { an ER. }\end{array}$ \\
\hline Illustrate & To use an ER to describe or explain a scientific phenomenon. \\
\hline Infer & To use an ER to logically establish knowledge through deductive reasoning. \\
\hline Outline & To give the main features of scientific phenomena using an ER. \\
\hline
\end{tabular}

those identified by other researchers (e.g., Mnguni, 2019a, 2019b; Mnguni et al., 2016).

While several visualization skills have been identified, the current research focused on some of the visualization skills (see Table 1, Mnguni, 2018), which have been previously identified as being utilized in these stages of visualization (e.g., Mnguni, 2018, 2019a, 2019b; Mnguni et al., 2016). Even though these skills can be defined and tested generically, as is the case in Bloom's taxonomy, in the current research, these skills were defined as visualization skills within the context of visual literacy as they utilized biology-specific ERs. This means students were expected to use these skills to reason with the ER using existing content knowledge. The research scope focused only on these skills as a preliminary effort to inform a larger-scale study that would involve other visualization skills.

According to Schönborn and Anderson's (2009) model of factors determining students' ability to interpret ERs, an effective demonstration of visualization skills depends on the student's discipline conceptual knowledge related to the ER, their ability to reason with the ER as well as the nature of the ER. In the current research, therefore, students were presented with relevant content knowledge to ensure that they have sufficient content required to conceptualize knowledge presented in the ER. Additionally, the ERs used were validated by the relevant education authority and used by teachers in their regular teaching activities.

\section{Research Design}

The current research was guided by a positivist research paradigm (Cresswell, 2014; Kaboub, 2008), which uses standardized, systematic knowledge generation processes through quantitative research methods to enhance precision in describing parameters and their relationship. To this end, a quantitative approach was used to describe phenomena observed in the sampled population and make inferences to a larger population from which the sample was derived. The observations were made through a quasi-experimental research design that utilized an assessment test as an instrument for data collection from a purposively selected sample of participants. Data analysis was 
Table 2. A summary of the stages of the study in which the participants were involved

\begin{tabular}{ll}
\hline Activity & Purpose \\
$\begin{array}{l}\text { Self-study } \\
\text { Pre-test }\end{array}$ & $\begin{array}{l}\text { To enable the participants an opportunity to have an understanding of the basic concepts of mitosis. } \\
\text { To assess the participants' understanding of mitosis before exposure to the intervention in order to be } \\
\text { able to determine the impact of the intervention. }\end{array}$ \\
$\begin{array}{ll}\text { Exposure to an } \\
\text { animation }\end{array}$ & $\begin{array}{l}\text { to determine if exposure to the animation could enhance the participants' visualization skills and } \\
\text { reduce learning difficulties related to basic concepts of mitosis }\end{array}$ \\
& $\begin{array}{l}\text { To assess the participants' understanding of mitosis after the exposure to the intervention in order to be } \\
\text { able to determine the impact of the intervention. }\end{array}$
\end{tabular}

guided by the classical test theory (Allen \& Yen, 2002; Hambleton et al., 1991), suggesting that a respondents' observed score on a test is equal to the sum of their true score and error score. It, therefore, relies on the measure of reliability and validity to generate logical findings.

\section{Study Context and Sampling}

Data were collected from a purposively selected group of 67 Grade 10 biology students from a township school in the East of Johannesburg, South Africa, in 2018. The school was purposively selected because it is an under-resourced independent school that has not received sophisticated ICT infrastructure resources, such as smart boards and mobile computers, for teaching and learning before the current study. As such, the underlying assumption is that students in this school, unlike other local schools, have not been exposed to animations extensively due to a lack of related infrastructure. This would be useful in the current research to determine the extent to which animation could affect students' visualization skills. Participants were all aged between 15 and 18. They were randomly assigned to the experimental group $(n=36)$ and the control group $(n=31)$. We did not consider gender differences as we did not have a scientifically sound and ethical justification for comparing boys and girls in terms of their cognitive abilities.

\section{Instrument Design and Development}

An assessment test was used for data collection. As mentioned in the theoretical framework, in designing the items in the test, we used the Mnguni's (2019a) instrument to assess visualization in biology as a guide. Specifically, the test, which comprised of two main sections, probed visualization skills (see Table 1) within the context of mitosis. In this instance, the items did not ask the student content knowledge questions; instead, they required them to demonstrate the visualization skills within mitosis. Scoring, therefore, focused on the extent to which the visualization skills were demonstrated, as defined in Table 1 . The first section of the test required the students to demonstrate visualization skills concerning an animation and static 2D diagrams of mitosis. The second section asked students to state visualization difficulties they encounter when learning through the animation and static 2D diagrams of mitosis. Specifically, the items in this section used Likert scale items to determine whether students had visualization difficulties related to Analyzing, Describing, Illustrating, Inferring, and Outlining content related to mitosis as depicted in the animation and static, 2D diagrams.

We developed the instrument and validated it through a panel of experts as well as a pilot group. The purpose here was to enhance the face, content, and criterion-related validity of the instrument. From the nine experts who validated the instruments, a content validity index of $87 \%$ was obtained, which suggested that the instrument was 'fit for purpose.' The pilot group was also able to complete the test within 30 minutes, and no technical or content-related concerns were raised. We were, therefore, satisfied that the instrument was valid. Reliability was also determined from the pilot data. Here a Cronbach alpha coefficient of .83 was obtained, suggesting that the instrument was statistically reliable.

\section{Data Collection and Analysis}

As mentioned earlier, the current research followed a quasi-experiment design. This design was preferred because the study focused on one school with limited sample size, limited randomization of sampling, and it reduced the possibility of ecological validity. A quasiexperiment design also allows for the generalization of findings. The participants participated in the study in four stages, as shown in Table 2.

In the study, therefore, the participants were assigned randomly into the control and experimental group. Both groups were subsequently given self-study materials through which they could learn the basic introductory concepts of mitosis. These materials described the process of mitosis and its various phases using text, diagrams, and pictures. The learning outcomes of this exercise was that and the end, students could be able to define mitosis; describe the process and phases of mitosis; explain the significance of mitosis; discuss the characteristics of the different phases of mitosis; and, determine the effect of mitotic cell division on the number and characteristics of chromosomes and cells. The self-study materials included summary notes, a textbook, and worksheets accredited by the Department of Basic Education. These were given to the students to work with for two days (over a weekend). The assessment test was then administered to all participants 
as a 'pre-test' after the two days of self-study (on a Monday).

A day after the pre-test (on a Tuesday), both groups were given a teacher-guided lesson facilitated by the same teacher in both groups. In the control group, no additional teaching and learning resources were provided. The teacher used the materials that were provided for the self-study to facilitate learning. This included presenting content, describing and explaining concepts, as well as solving problems with students. In the experimental group, however, an animation was used as an added teaching and learning resource. This animation was used to demonstrate the process of mitosis using animated graphics. In both these sessions, the learning outcomes were similar to those of the selfstudy.

The animation used in the experimental group was obtained from an open educational resource. It depicted the process of mitosis over three minutes and forty-one seconds. The different phases of mitosis were graphically presented using various animated shapes, colors, onscreen text, and narration. The onscreen text included labels to the various depictions, while the narration explained the entire process. Additional onscreen text corresponding to the narration was removed in line with the redundancy principle of multimedia learning (Moreno \& Mayer, 1999). The content presented was in line with the learning objectives of the session, as described above. We selected the animation using Moreno and Mayer's (1999) principles of multimedia learning. The teacher facilitated the animation presentation by pausing and clarifying wherever she saw fit and where students requested clarity and explanations.

A post-test identical to the pre-test was administered to the participants in both groups a day after the teacherfacilitated lessons. Students' responses were scored against a set of correct answers prepared by the researcher and moderated through the panel of experts. The emerging raw scores obtained by the students were then concerted to percentage scores to compare student performance. This is also in line with the view that tests measuring variables such as ability may use interval or ratio scales where they "measure the same variable with equal intervals in the level of difficulty" (Mnguni et al., 2016). All data were then analyzed quantitatively using SPSS to determine the extent to which the animation could have affected the students' visualization skills related to basic introductory concepts of mitosis. This was because the animation was the unique variable deliberately added to the experimental group.

The student's $t$-test (t-test) was used to test the hypothesis for comparison of means between the groups. This parametric method was used because the variables were on a continuous scale and normally distributed. Additionally, the student's $t$-test was used because the comparison of means was between two groups. There was no need for multiple comparisons as a unique $P$-value is observed. Therefore, tests such as the ANOVA and ANCOVA, which compare means among three or more groups, were not used. This was also because the current study did not compare the dependent variable and a categorical independent variable while statistically controlling for covariates' effects.

\section{RESULTS}

\section{Impact on Visualization Skills}

The pre-test results showed that both groups had relatively poor visualization skills related to basic concepts of mitosis. For example, in the pre-test, the control group had a combined average score of $34.16 \%$ $(S D=8.58)$, while the experimental group had an average score of $28.43 \%(S D=8.08)$. While the scores were low in both groups, a t-test showed that there was a significant difference between them $(p=.0065)$. The pre-test results (Table 3) also show that in the control group, students performed poorly in tasks that required them to analyze an ER to identify cell components during mitosis; infer based on the information presented in the ER to calculate the number of cells after several stages of cell division; and, outline the sequence of mitosis phases and the phases of mitosis graphically. In the experiment group, students performed poorly in tasks that required them to outline the phases of mitosis and the sequence of mitosis phases graphically, describe the significance of mitosis; and, analyze an ER to identify the cell's components during mitosis.

In the post-test, the control group results showed that students' performance was poorer than in the pre-test, even though this group was not exposed to the animation. As shown in Table 4, the average control group mean score dropped from $34 \%(S D=8.58)$ to $31 \%$ $(S D=11.36)$. However, the difference was not statistically significant $(p>.05)$ even though the variances were significantly different $(p=.030)$. The small effect size was also detected in this instance (i.e., Cohen's $d=.29$ ), suggesting that the mean difference was trivial.

In the experimental group, however, students' average performance increased on from, $28.43 \%$ (SD = $8.08)$ to $51 \%(S D=9.41)$. The difference was statistically significant $(p<.001)$, even though there was no statistically significant difference between the variances $(p=.403)$ (Table 5). Effect size in this regard was large (i.e., Cohen's $d=, 2.62$ and Gates' delta =, 2.84), confirming that the difference between the means was statistically significant.

Notably, the improvement was highest (over 30\% improvement) in the tasks that required students to use an ER (diagram) to illustrate the different phases of 
Table 3. The scores obtained by participating students in the pre-and post-tests

\begin{tabular}{|c|c|c|c|c|c|c|c|c|c|}
\hline \multirow{3}{*}{$\begin{array}{l}\text { Visualization } \\
\text { skills } \\
\end{array}$} & \multirow{3}{*}{ Task } & \multicolumn{4}{|c|}{ Control Group } & \multicolumn{4}{|c|}{ Experimental Group } \\
\hline & & \multicolumn{2}{|c|}{ Pre-test } & \multicolumn{2}{|c|}{ Post-test } & \multicolumn{2}{|c|}{ Pre-test } & \multicolumn{2}{|c|}{ Post-test } \\
\hline & & Mean & S.D. & Mean & S.D. & Mean & S.D. & Mean & S.D. \\
\hline \multirow[t]{2}{*}{ Analyzing } & Identifying cell components during mitosis & 10 & 15 & 14 & 13 & 21 & 19 & 50 & 19 \\
\hline & $\begin{array}{l}\text { Identifying the correct number of chromosomes } \\
\text { in the cell during mitosis }\end{array}$ & 48 & 51 & 71 & 46 & 50 & 51 & 56 & 50 \\
\hline \multirow[t]{4}{*}{ Describing } & Describing the process of cell division & 71 & 46 & 58 & 50 & 39 & 49 & 47 & 51 \\
\hline & Defining mitosis & 81 & 36 & 66 & 37 & 58 & 41 & 75 & 41 \\
\hline & Describing the phases of mitosis & 35 & 49 & 19 & 40 & 14 & 35 & 56 & 50 \\
\hline & Explaining the significance of mitosis & 60 & 49 & 50 & 50 & 27 & 45 & 40 & 50 \\
\hline \multirow[t]{5}{*}{ Illustrating } & Listing the characteristics of the anaphase & 69 & 47 & 39 & 50 & 43 & 50 & 64 & 39 \\
\hline & Listing the characteristics of the Interphase & 42 & 51 & 47 & 49 & 41 & 50 & 71 & 40 \\
\hline & Listing the characteristics of the Metaphase & 71 & 46 & 52 & 51 & 36 & 49 & 89 & 32 \\
\hline & Listing the characteristics of the Prophase & 42 & 50 & 32 & 48 & 31 & 47 & 86 & 35 \\
\hline & Listing the characteristics of the Telophase & 74 & 44 & 52 & 51 & 53 & 51 & 92 & 28 \\
\hline Inferring & $\begin{array}{l}\text { Calculating the number of cells after several } \\
\text { stages of cell division }\end{array}$ & 29 & 46 & 55 & 51 & 39 & 49 & 67 & 48 \\
\hline \multirow[t]{2}{*}{ Outlining } & Generating a correct sequence of mitotic phases & 19 & 40 & 35 & 49 & 36 & 49 & 86 & 35 \\
\hline & Describing the process of mitosis & 84 & 37 & 84 & 37 & 64 & 49 & 89 & 32 \\
\hline
\end{tabular}

Table 4. A t-test comparing the results of the control group in the pre-and post-test

Levene's Test for

Equality of Variances

\begin{tabular}{|c|c|c|c|c|c|c|c|c|c|}
\hline & \multirow[t]{2}{*}{ F } & \multirow[t]{2}{*}{ Sig. } & \multirow[t]{2}{*}{$\mathrm{t}$} & \multirow[t]{2}{*}{ df } & \multirow{2}{*}{$\begin{array}{l}\text { Sig. (2- } \\
\text { tailed) }\end{array}$} & \multirow{2}{*}{$\begin{array}{c}\text { Mean } \\
\text { Difference }\end{array}$} & \multirow{2}{*}{$\begin{array}{l}\text { Std. Error } \\
\text { Difference }\end{array}$} & \multicolumn{2}{|c|}{$\begin{array}{c}\text { 95\% Confidence Interval of } \\
\text { the Difference }\end{array}$} \\
\hline & & & & & & & & Lower & Upper \\
\hline $\begin{array}{l}\text { Equal variances } \\
\text { assumed }\end{array}$ & 4.963 & .030 & 1.150 & 60 & .255 & 2.94097 & 2.55683 & -2.17345 & 8.05539 \\
\hline $\begin{array}{l}\text { Equal variances } \\
\text { not assumed }\end{array}$ & & & 1.150 & 55.835 & .255 & 2.94097 & 2.55683 & -2.18131 & 8.06325 \\
\hline
\end{tabular}

Table 5. A t-test comparing the results of the experiment group in the pre-and post-test

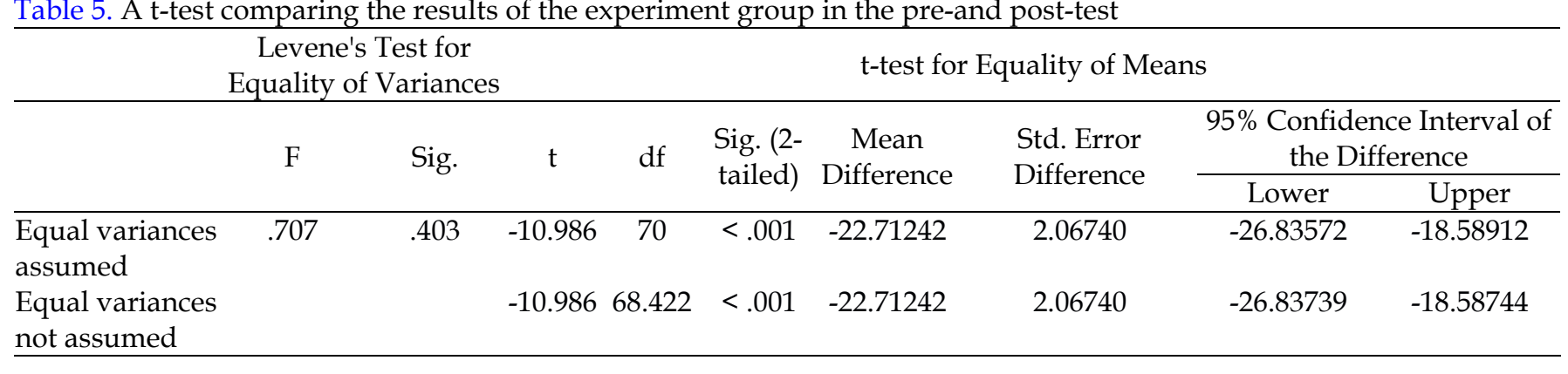

mitosis, outline the sequence of mitosis phases, and describe the phases of mitosis (see Table 1). The difference was least (less than $10 \%$ improvement) in the tasks that required students to describe, using drawing (i.e., generate an ER), the process of cell division, and analyze diagrams to identify the correct number of chromosomes in the cell during mitosis.

Comparing the control group and the experiment group's post-test results also showed that the experimental group performed better than the experimental group. The difference in this regard was statistically significant $(p<.001)$ (Table 6). Levene's Test for Equality of Variances in this instance showed that the variances were not statistically significant. These results show that the animation had a significant impact on students' visualization skills.

\section{Impact on Learning Difficulties}

Pre-test results also showed that most students in both groups indicated that they had visualization difficulties related to comprehending information embedded in an ER (Table 7). This was supported by the fact that most students could not understand the meaning of symbols used in the representation. Similarly, most students could not interpret pictures or describe what is shown in an ER. Notably, however, fewer visualization difficulties were reported in the experimental group following exposure to the animation. For example, the number of students 
Table 6. A t-test comparing the results of the control group and the experiment group in the post-test

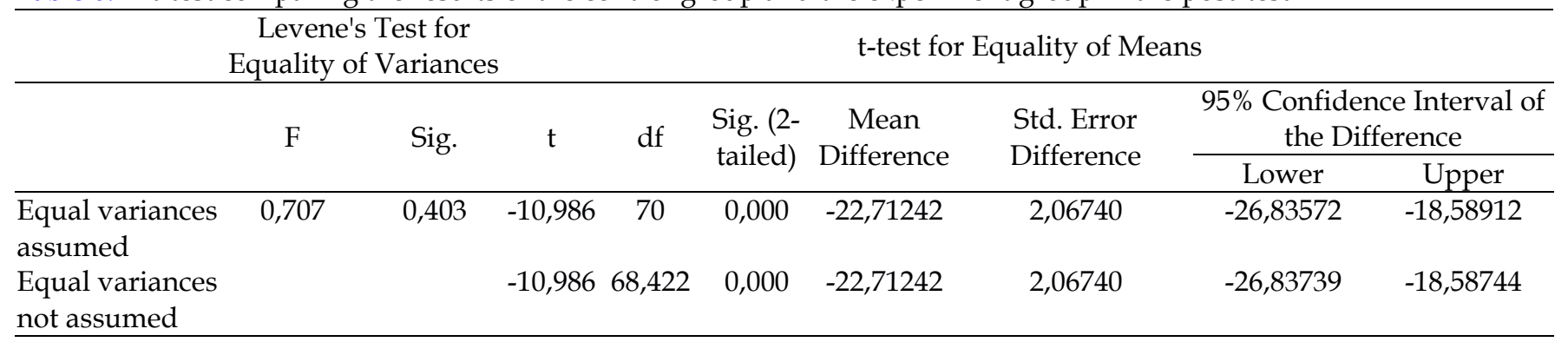

Table 7. Reported visualization difficulties

\begin{tabular}{|c|c|c|c|c|}
\hline Item & $\begin{array}{l}\text { Control Group } \\
\text { (Post-test) }(\%)\end{array}$ & $\begin{array}{c}\text { Control } \\
\text { Group (Pre- } \\
\text { test) }(\%)\end{array}$ & $\begin{array}{c}\text { Experimental } \\
\text { Group (Pre- } \\
\text { test) }(\%)\end{array}$ & $\begin{array}{c}\text { Experimental } \\
\text { Group (Post- } \\
\text { test) }(\%)\end{array}$ \\
\hline $\begin{array}{l}\text { Comprehending information on mitosis when being taught } \\
\text { through ER. }\end{array}$ & 89 & 85 & 76 & 50 \\
\hline Illustrating the process of mitosis using a drawing & 60 & 63 & 67 & 36 \\
\hline $\begin{array}{l}\text { Understanding the meaning of symbols used in the ER } \\
\text { about mitosis }\end{array}$ & 68 & 67 & 56 & 33 \\
\hline Interpreting pictures of the phases of mitosis. & 67 & 62 & 78 & 47 \\
\hline Following the pace of animation & 43 & 50 & 56 & 68 \\
\hline Concentrating when learning mitosis through animation & 36 & 40 & 43 & 22 \\
\hline Describing what is shown in an ER on Mitosis & 44 & 50 & 36 & 44 \\
\hline Interpreting pictures that show the process of mitosis & 71 & 72 & 82 & 58 \\
\hline $\begin{array}{l}\text { Predicting what will happen next in the process of mitosis } \\
\text { that is illustrated through an ER }\end{array}$ & 53 & 55 & 44 & 36 \\
\hline $\begin{array}{l}\text { Analyzing an ER showing mitosis to identifying phases of } \\
\text { Mitosis }\end{array}$ & 83 & 80 & 80 & 41 \\
\hline
\end{tabular}

reporting difficulty comprehending information from an ER dropped from $76 \%$ to $50 \%$.

Similarly, the number of students who indicated that they had visualization difficulties interpreting pictures dropped from $78 \%$ to $47 \%$. However, more students reported that they had difficulty following the pace of an animation. In this case, the number increased from $56 \%$ to $68 \%$.

A t-test showed a significant difference in the reported visualization difficulties within the experimental group when comparing the pre-test and post-test results $(p=.015)$. Results also showed that within the control group, there was no significant difference in the reported visualization difficulties $(p=$ .890). However, when comparing the control group and experimental group, in the pre-test, there was also no significant difference in the reported visualization difficulties $(p=.959)$. There was, however, a significant difference in the reported visualization difficulties between the two groups in the post-test $(p=.006)$. These results suggest that exposure to the animation may be associated with lesser visualization difficulties.

\section{DISCUSSION}

Previous research has focused on using ERs to improve students' understanding of content knowledge and the development of scientific skills, including problem-solving skills (e.g., Reddy \& Mint, 2017; Rice, 2013). There is, however, limited research that attempts to integrate cognitive skills, scientific skills, and content understanding to explore strategies for developing and evaluating these among students. For example, several researchers have defined visual literacy as a context and content free concept which involves internalization, conceptualization, and externalization of ERs (e.g., Arneson \& Offerdahl, 2018; Avgerinou \& Ericson, 1997; Ealy, 2018; Mnguni, 2014). As argued by Mnguni (2019a), a limited number of researchers (e.g., Anderson et al., 2013) have recognized that by nature, ERs use disciplinespecific semiotics, which may not be shared between different disciplines. Additionally, there has been a lack of research that explores cognitive visualization skills and content understanding as one unit. For example, scholars have previously investigated students' visualization skills (e.g., Mnguni et al., 2016), while others have explored the effect of ERs on students understanding of content knowledge (e.g., Reddy \& Mint, 2017; Rice, 2013).

However, the current research has contributed to the literature by assessing students' visualization skills that rely on the nonverbal visual cognitive processes necessary for content understanding. As explained by Schönborn and Anderson (2009), effective learning from ERs is dependent on students' reasoning skills and availability of content knowledge. Consequently, we 
argue that learning from ERs requires students to have relevant discipline-specific visualization skills, with which they could decode and encode ERs through visualization for meaningful learning. By assessing visualization skills, the current research has shown that when learning with ERs, students use their cognitive reasoning skills to engage abstract content knowledge embedded in the model and the model and its features concurrently. This view is supported by Anderson et al. (2013), who argue that learning from ERs is affected by multiple factors, including conceptual knowledge, the mode of presenting knowledge (i.e., the ER), and the students' reasoning skills. The current research expands on this by showing that teaching using ERs affects not only students' content understanding but also their visualization skills. This finding, however, suggests that teachers may have to reconsider their instructional objectives to include visualization skills.

The current research has also shown that visualization skills could be developed simultaneously with content knowledge rather than independently. For example, for a student to be able to illustrate the different phases of mitosis using an ER, they require visualization skills which are a combination of content knowledge of the phases of mitosis, cognitive skills for illustrating this knowledge, and knowledge of the characteristics of the ER which they will utilize. A question that follows from the above then is, how are visualization skills be developed? Previous research has shown that it is essential for teachers to facilitate learning through ERs because students may not have the necessary skills to learn through ER (Ealy, 2018). The current research findings support this view by showing that a teacherfacilitated use of animations could enhance students' visualization skills. For example, the current research has found, in the experimental group, that students' ability to use diagrams to illustrate the different phases of mitosis using an ER, outline the sequence of mitosis phases, and describe the phases of mitosis improved significantly. Additionally, students' ability to describe the process of cell division using a diagram and analyze diagrams to identify the correct number of chromosomes in the cell during mitosis also improved. These results show that students' visualization skills improved as a result of learning mitosis using an animation.

The improvement in students' visualization skills was also supported by the drop in the number of reported visualization difficulties associated with the use of ERs also dropped. Previous research has shown, for example, that when learning with ERs, students may encounter reasoning difficulties that may jeopardize their conceptual understanding (e.g., Anderson et al., 2013; Schönborn \& Anderson, 2010). Several strategies to address these difficulties have been recommended (e.g., Clark \& Mayer, 2016; Mayer, 2014; Moreno \& Mayer, 1999). The current research adds to this body of knowledge by showing that ERs can be used both as teaching tools for the development of visualization skills and reducing visualization difficulties. For example, in the pre-test, students reported that they had visualization difficulties analyzing an ER to identify cell components during mitosis; using the information presented in the ER to calculate the number of cells after several stages of cell division; outlining the sequence of mitosis phases and the phases of mitosis graphically; outlining the phases of mitosis and the sequence of mitosis phases graphically, describing the significance of mitosis; and, analyzing an ER to identify the components of the cell during mitosis. In the post-test, however, the experimental group showed a significant improvement as fewer students reported visualization difficulties associated with using ERs. For example, fewer students reported an inability to comprehend information from an ER, interpreting pictures. These results also suggest that exposure to the animation may have had a positive effect on reducing visualization difficulties.

The context in which the current research was carried out is also significant to mention. For example, several researchers have argued that the lack of resources in rural and township schools hinders effective teaching and learning. The findings of the current research suggest that the deployment of ICT infrastructure in such schools may yield positive teaching and learning results. However, it is essential to ensure that ERs adhere to relevant guidelines such as Mayer's (2014) principles of multimedia learning, such as the use of teachers as facilitators during ER-based learning.

\section{CONCLUSION}

In response to the research question of the current research; therefore, the findings show that using an animation does improve students' visualization skills related to basic concepts of mitosis. The animation also reduces visualization difficulties related to visual learning in biology. While the current research focused on a limited number of visualization skills within a smaller sample size, the current findings lay a foundation for further research into strategies for enhancing teaching and learning using ERs. There is, therefore, a need for a broader research to determine the impact of ERs, such as animations, on students' visualization skills related to biological concepts. We recommend that animations be used for student development which includes visual literacy. The findings are particularly important for teachers and instructional designers who have adopted animations as part of their online teaching tools.

Author contributions: All authors have sufficiently contributed to the study, and agreed with the results and conclusions.

Funding: No funding source is reported for this study.

Declaration of interest: No conflict of interest is declared by authors.

Acknowledgements: We want to thank all the students who participated in the research. 
Compliance with ethical standards: The study was approved by the Ethics Review Committee in the College of Education, University of South Africa, reference number 2018/05/16/61642916/05/MC.

Ethical approval: The research was conducted following the institutional and national research committee's ethical standards and with the 1964 Helsinki declaration and its later amendments or comparable ethical standards. The study was approved by the Ethics Review Committee in the College of Education, University of South Africa.

Consent statement: The research was approved by the University of South Africa's College Of Education Ethics Review Committee (Reference number 2018/05/16/61642916/05/MC). All participants consented to participate voluntarily in the research. The research was conducted in accordance with the ethical standards of the institutional and/or national research committee and with the 1964 Helsinki declaration and its later amendments or comparable ethical standards.

\section{REFERENCES}

Airey, J., \& Linder, C. (2009). A disciplinary discourse perspective on university science learning: Achieving fluency in a critical constellation of modes. Journal of Research in Science Teaching, 46(1), 27-49. https:// doi.org/10.1002/ tea.20265

Allen, M. J., \& Yen, W. M. (2002). Introduction to Measurement Theory. Waveland Press.

Anderson, T. R., Schönborn, K. J., du Plessis, L., Gupthar, A. S., \& Hull, T. L. (2013). Identifying and developing students' ability to reason with concepts and representations in biology. In D. Treagust, \& C.-Y. Tsui (Eds.). Multiple representations in biological education (pp. 19-38). Springer. $\quad$ https://doi.org/10.1007/978-94-0074192-8_2

Arneson, J. B., \& Offerdahl, E. G. (2018). Visual literacy in Bloom: Using Bloom's taxonomy to support visual learning skills. CBE Life Sciences Education, 17(1), 1-8. https:/ / doi.org/10.1187/cbe.17-08-0178

Avgerinou, M., \& Ericson, J. (1997). A review of the concept of visual literacy. British Journal of Educational Technology, 28(4), 280-291. https:// doi.org/10.1111/1467-8535.00035

Chang, H. Y., Quintana, C., \& Krajcik, J. S. (2010). The impact of designing and evaluating molecular animations on how well middle school students understand the particulate nature of matter. Science Education, 94(1), 73-94. https://doi.org/10.1002/ sce. 20352

Clark, R. C., \& Mayer, R. E. (2016). E-learning and the science of instruction: Proven guidelines for consumers and designers of multimedia learning. John Wiley \& Sons. https:/ / doi.org/10.1002/9781119239086

Cresswell, J. W. (2014). Research design: Qualitative, quantitative, and mixed methods approaches (4th ed.). Sage publications.

Dries, D. R., Dean, D. M., Listenberger, L. L., Novak, W. R., Franzen, M. A., \& Craig, P. A. (2016). An expanded framework for biomolecular visualization in the classroom: Learning goals and competencies. Biochemistry and Molecular Biology Education, 45(1), 69-75. https://doi.org/10.1002/ bmb.20991

Ealy, J. B. (2018). Assessment of students' external representations of mmCIF entries and their biochemical knowledge. Biochemistry and Molecular Biology Education, 46(6), 634-643. https://doi.org/ 10.1002/bmb.21183

Hambleton, R., Swaminathan, H., \& Rogers, H. (1991). Fundamentals of item response theory. Sage Publications, Inc.

Kaboub, F. (2008). Positivist paradigm. Encyclopaedia of Counselling, 2(2), 343.

Krathwohl, D. R., \& Anderson, L. W. (2001). A taxonomy for learning, teaching, and assessing: A revision of Bloom's taxonomy of educational objectives. Addison Wesley Longman.

Kühl, T., Navratil, S. D., \& Münzer, S. (2018). Animations and static pictures: the influence of prompting and time of testing. Learning and Instruction, 58, 201-209. https:/ / doi.org/10.1016/j.learninstruc.2018.07.006

Mackenzie, N., \& Knipe, S. (2006). Research dilemmas: Paradigms, methods and methodology. Issues in Educational Research, 16(2), 193-205.

Mayer, R. E. (2014). The Cambridge handbook of multimedia learning ( $2^{\text {nd }}$ ed). Cambridge University Press. https:/ / doi.org/10.1017/CBO9781139547369

Milner-Bolotin, M., \& Nashon, S. M. (2012). The essence of student visual-spatial literacy and higher-order thinking skills in undergraduate biology. Protoplasma, 249(1), 25-30. https:// doi.org/10.1007 / s00709-011-0346-6

Mnguni, L. (2018). A description of visual literacy among third year biochemistry students. Journal of Baltic Science Education, 17(3), 486-495.

Mnguni, L. (2019a). The development of an instrument to assess visuo-semiotic reasoning in biology. Eurasian Journal of Educational Research, 19(82), 121136.

Mnguni, L. (2019b). An assessment of visuo-semiotic reasoning skills among pre-service biology teachers. XIII Conference of the European Science Education Researchers Association. 26-30 August 2019. Faculty of Education, University of Bologna, Italy.

Mnguni, L. E. (2014). The theoretical cognitive process of visualization for science education. SpringerPlus, 3(1). https:/ / doi.org/10.1186/2193-1801-3-184

Mnguni, L., Schönborn, K., \& Anderson, T. (2016). Assessment of visualisation skills in biochemistry students. South African Journal of Science, 112(9-10), $1-8$. 
Moreno, R., \& Mayer, R. E. (1999). Cognitive principles of multimedia learning: The role of modality and contiguity. Journal of Educational Psychology, 91(2), 358-368. https://doi.org/10.1037/0022-0663.91.2. 358

Offerdahl, E. G., Arneson, J. B., \& Byrne, N. (2017). Lighten the load: Scaffolding visual literacy in biochemistry and molecular biology. CBE-Life Sciences Education, 16(1), es1. https://doi.org/ 10.1187/cbe.16-06-0193

Oliver-Hoyo, M., \& Babilonia-Rosa, M. A. (2017). Promotion of spatial skills in chemistry and biochemistry education at the college level. Journal of Chemical Education, 94(8), 996-1006. https: / / doi.org/10.1021/acs.jchemed.7b00094

Paivio, A. (2007). Mind and its evolution: A dual coding theoretical approach. Lawrence Erlbaum Associates Publishers.

Palmer, M. S., \& Matthews, T. (2015). Learning to see the infinite: Measuring visual literacy skills in a 1styear seminar course. Journal of the Scholarship of Teaching and Learning, 15(1), 1-9.

Prinsloo, C. H., Rogers, S. C., \& Harvey, J. C. (2018). The impact of language factors on student achievement in science. South African Journal of Education, 38(1), 1-14. https:/ / doi.org/10.15700/ saje.v38n1a1438

Reddy, M., \& Mint, P. P. (2017). Impact of SimulationBased Education on Biology Student's Academic Achievement in DNA Replication. Journal of Education and Practice, 8(15), 72-75.

Rice, S. C. (2013). Using interactive animations to enhance teaching, learning, and retention of respiration Pathway concepts in face-to-face and online high school, undergraduate, and continuing education learning Environments. Journal of Microbiology \& Biology Education: JMBE, 14(1), 113115. https:/ / doi.org/10.1128/jmbe.v14i1.509

Schönborn, K. J., \& Anderson, T. R. (2009). A model of factors determining students' ability to interpret external representations in biochemistry. International Journal of Science Education, 31(2), 193232. https:/ / doi.org/10.1080/09500690701670535

Schönborn, K. J., \& Anderson, T. R. (2010). Bridging the educational research-teaching practice gap: Foundations for assessing and developing biochemistry students' visual literacy. Biochemistry and Molecular Biology Education, 38(5), 347-354. https://doi.org/10.1002/bmb.20436

Somekh, B., \& Lewin, C. (2005). Research methods in the social sciences. Sage.

Stebner, F., Kühl, T., Höffler, T. N., Wirth, J., \& Ayres, P. (2017). The role of process information in narrations while learning with animations and static pictures. Computers $\mathcal{E}$ Education, 104, 34-48. https:/ / doi.org/ 10.1016/j.compedu.2016.11.001

Tsui, C.-Y., \& Treagust, D. F. (2003). Genetics reasoning with multiple external representations. Research in Science Education, 33(1), 111-135. https://doi.org/ 10.1023/A:1023685706290

Vygotsky, L. S. (1978). Mind in society: The development of higher psychological processes. Harvard University Press.

\section{http://www.ejmste.com}

